\title{
A Method for Quantitative Evaluation of Seismic Stability of Loess Slope Based on the Shaking Table Model Test
}

\author{
Pu Xiaowu, ${ }^{1,2,3}$ Wang Lanmin $\mathbb{D D}^{1,2,3}$ Wang Ping $\mathbb{D}^{3},{ }^{3}$ Chai Shaofeng, ${ }^{3}$ and Xu Shiyang ${ }^{3}$ \\ ${ }^{1}$ Key Laboratory of Mechanics on Disaster and Environment, Western China, Ministry of Education, Lanzhou University, \\ Lanzhou 730000, Gansu, China \\ ${ }^{2}$ College of Civil Engineering and Mechanics, Lanzhou University, Lanzhou 730000, Gansu, China \\ ${ }^{3}$ Key Lab on Loess Earthquake Engineering, China Earthquake Administration, Lanzhou 730000, China \\ Correspondence should be addressed to Wang Lanmin; wanglm2304@126.com and Wang Ping; 12786355@qq.com
}

Received 3 February 2021; Revised 3 August 2021; Accepted 26 October 2021; Published 3 December 2021

Academic Editor: Roberto Nascimbene

Copyright (c) $2021 \mathrm{Pu}$ Xiaowu et al. This is an open access article distributed under the Creative Commons Attribution License, which permits unrestricted use, distribution, and reproduction in any medium, provided the original work is properly cited.

\begin{abstract}
The large-scale shaking table model test, which can directly reproduce the process of slope instability and failure, is an important technical means for the prediction and evaluation of slope seismic stability. However, up to now, the systematic slope stability evaluation method based on the shaking table slope model test has not been established, which limits the application of the expensive shaking table model test in slope seismic design. Therefore, the slope stability evaluation method based on the model test needs to be developed and innovated. In this research, through three loess slope model tests with different rainfall, according to the change law of the peak value of transfer function spectrum, combined with the macrodestructive characteristics of the slope model, an accurate calculation method of the critical instability acceleration of the slope is proposed. Based on the behavior similarity theory, for the shaking table model test of slope whose soil cohesion cannot meet the similarity ratio, the reduction method of applying the critical instability acceleration obtained from the model test to prototype slope is proposed. Based on firstorder natural frequency and damping ratio extracted from the TF spectrum curve, a calculation method for the stability factor $F_{s}$ of loess slope based on the shaking table model test is proposed, and the stability factors of loess slope under the action of different seismic ground motion would be quantitatively calculated. The above methods provide another effective way for qualitative prediction and evaluation of seismic stability of loess slope.
\end{abstract}

\section{Introduction}

The Loess Plateau is one of the cradles of Chinese civilization, which created brilliant civilization in the Chinese history. However, due to its arid and rainless climate, ravine topography, frequent earthquakes (Figure 1(a)), and various geological disasters, it has become one of the underdeveloped areas in modern China. At present, with the development of the western development strategy, the Loess Plateau in China has become the key area of the national social and economic development strategy. In recent years, airports, expressways, railways, and other major infrastructures have been widely implemented in this area. The completion and operation of these infrastructure greatly facilitates people's life and promotes social and economic development. However, the large-scale engineering construction projects have changed the original landform of loess area and formed loess slopes of different scales, and slope instability and sliding have become a kind of frequent disasters in loess area [1] (Figure 1(b)). At present, the process of urbanization in the Loess Plateau is also advancing rapidly. Due to the ravine topography, flat and open construction land is very limited, and many places of the loess area restricted by the natural geographical conditions have to use a way of slope cutting and mountain cutting to obtain new construction land resources (Figure 1(c)), which leads to a large number of new cities and towns adjacent to the side of high slopes (Figure 1(d)); thus, there are major potential safety risks [2]. According to the seismic parameter zonation map of China (GB 18306-2015) [3], the area of 


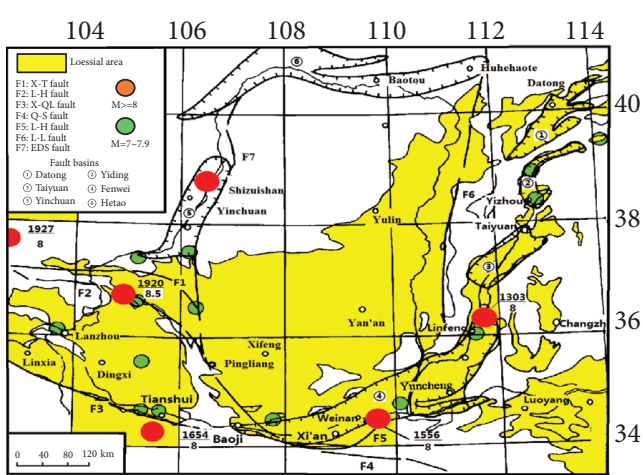

(a)

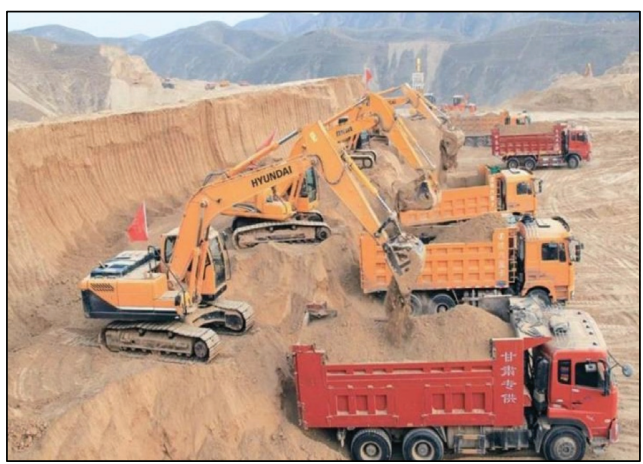

(c)

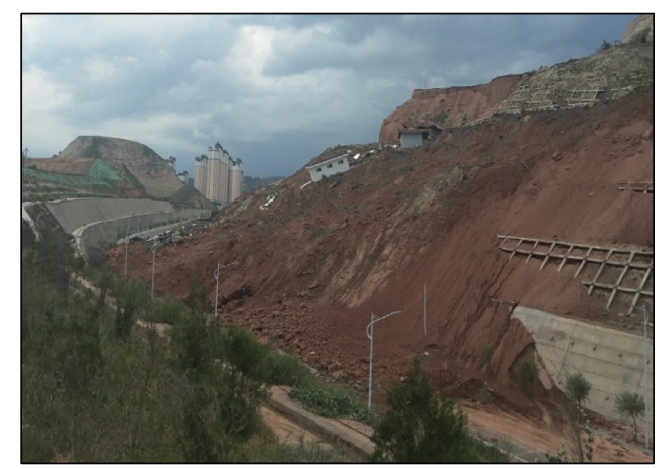

(b)

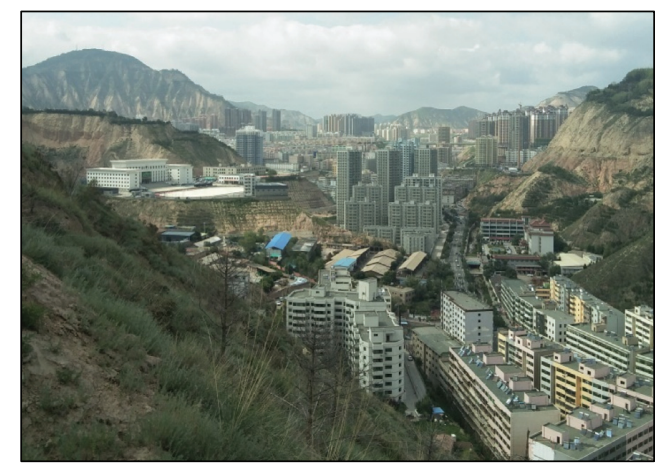

(d)

FIGURE 1: Engineering activities and earthquake landslide risk in the Loess Plateau. (a) Distribution of historical earthquakes. (b) Sliding of an engineering slope. (c) Cutting slope to making land. (d) Buildings adjacent to slopes.

basic seismic fortification intensity VII and above in the Loess Plateau accounts for $54.21 \%$. The potential earthquake disaster risk of cities and their major infrastructure projects in the high seismic intensity area is very high. Loess has physical and mechanical properties that exhibit water sensitivity and dynamic vulnerability [4]. When loess is immersed in water or undergoes strong earthquakes, its microstructure collapses, resulting in serious geotechnical hazards or engineering deterioration. Loess landslides induced by water or earthquakes have been the most prominent geological disasters in the loess areas of China [5]. Loess landslides induced by earthquakes are characterized by a high density, large scale, high sliding speed, and long sliding distance, making them very hazardous and destructive [6]. How to ensure the earthquake safety of cities and infrastructure in the Loess Plateau and minimize casualties and socioeconomic losses caused earthquake disaster are one of the scientific problems that need to be solved urgently [7].

In order to prevent and reduce the risk of loess earthquake landslide disaster, the seismic stability evaluation of loess slope is very important. At present, the seismic stability factor of slope is widely used as the seismic fortification index, and the quasistatic method or numerical simulation method is often used for slope seismic stability analysis and evaluation. The pseudostatic method uses PGA instead of the seismic action process, and the results are quite different from the actual situation. Numerical simulation method like finite element can overcome many limitations and shortcomings of the quasistatic method and can realize the deformation evolution and failure process of slope [8-10], which is a suitable choice for modeling slope stability with low cost and high accuracy [11-14]. Therefore, finite element is widely used in the stability evaluation of loess slope. However, since loess is a soil with special microstructure $[15,16]$, which is the main internal factor affecting its mechanical properties $[17,18]$, loess microstructure is easy to be damaged and failured under the action of external factors such as water and force, and the failure mode of loess under dynamic action is also very different with the different water content $[4,19]$, and the failure mechanism of loess slopes with different water content is very different under seismic dynamic action [20-24]. The simulation results of slope seismic stability by the finite element method highly depend on the soil constitutive equation, while the constitutive model considering loess microstructure is still in the exploratory stage [25]. So when the finite element method is used to analyze the seismic stability of loess slope, whether the nonlinear damage process of loess microstructure could be simulated is a challenging problem. Because the failure mode of loess is closely related to its stress state and water content, it is a difficult problem for the finite element method based on the assumption of continuous deformation to simulate the tensile failure under low confining pressure and low water content. Under the reciprocating action of seismic ground motion, the mechanical properties of soil 
mass at different positions of slope change differently $[20,26]$, and it is difficult to realize the spatial-temporal variation of mechanical properties of slope soil under seismic action by the finite element method. In view of the above problems, the large-scale shaking table test has been widely used in the prediction and evaluation of loess slope stability in recent years $[24,27,28]$. However, the shaking table model test about slope instability failure can only give the critical instability acceleration and cannot give quantitative evaluation results less than the critical instability acceleration, which is not convenient to compare with the stability factor calculated by other methods and which limits the application of the expensive shaking table model test in slope seismic design to a certain extent. In order to solve this problem, the calculation method of seismic stability factor of loess slope is established based on the shaking table model test, and the accurate calculation of the critical acceleration and the conversion method of the model test results applied to the prototype is proposed in this research, which provides an important quantitative basis for seismic design and engineering prevention of loess slope.

\section{Study Area}

The Loess Plateau is seated on the upper and middle stream of the Yellow River in northern China, and its total area is approximately $335,000 \mathrm{~km}^{2}$ with the thickness of loess deposit ranging from several meters to more than $500 \mathrm{~m}$ [4].The Loess Plateau is the largest continuous distribution area of loess in the world and has the thickest loess deposits and the most complicated topography, where major landforms are loess tableland, loess ridge and hillock, and valley terraces.

The Loess Plateau is one of the most tectonically active areas of the world and also one of the most intensely seismic activities' regions of the world. According to historical earthquake records, 367 earthquakes with magnitude greater than Ms 5.0 occurred in the region, and there are 7 events with magnitude equal or greater than Ms 8.0, 20 events with magnitude between Ms 7.0 and 7.9, and 71 events with magnitude between Ms 6.0 and 6.9, and more than 1.4 million people were killed by the earthquakes [29].

Loess is characterized by high porosity and weak cementation, and metastable scaffold pores are extremely well developed, which has extremely strong collapsibility and dynamic vulnerability [4]. In addition, topography of crisscross hills and gullies, earthquake-prone environment, and several factors combination make loess landslides and collapses be the most prominent geological disasters in the Loess Plateau $[4,6]$. In 1920, Haiyuan Ms 8.5 earthquake caused more than 270,000 deaths, among which more than 100,000 deaths were caused by loess landslides [6].

The Loess Plateau belongs to temperate continental monsoon climate, with an average annual precipitation of $400-600 \mathrm{~mm}$, and rainfall is concentrated from July to September, accounting for $70 \%$ of annual rainfall, which is prone to heavy rain in summer and continuous rainfall for many days in autumn. Therefore, rainfall is a main factor triggering loess landslide [30, 31].
Based on the practical needs of preventing and mitigating loess earthquake and landslide disasters, considering the above factors, a low-angle loess slope was selected as the research object in Lanzhou, located in the west of the Loess Plateau. A series of shaking table model tests to investigate the seismic stability of slope under different rainfall conditions were carried out.

\section{Shaking Table Model Test}

Three types of shaking table model tests of loess slopes with rainfall of $0 \mathrm{~mm}$ (natural state), $10 \mathrm{~mm}$, and $100 \mathrm{~mm}$, respectively, under seismic ground motion have been carried out successively, and the quantitative evolution law of physical quantities related to the slope models in the process of increasing loading intensity is comparatively analyzed, so as to establish the evaluation method of seismic stability of loess slope based on the shaking table model test.

For three model tests with different rainfall, model size, and physical and mechanical parameters, loading seismic waveform and making process of the slope model are basically the same, and the difference between them is rainfall and loading seismic wave intensity.

3.1. Test Equipment. The equipment for loading seismic ground motion in the model tests is a large two-way electric servo shaking table in Key Laboratory of Loess Earthquake Engineering, Lanzhou Institute of Seismology. The table size is $4 \mathrm{~m} \times 6 \mathrm{~m}$, the maximum loading weight is $25 t$, the maximum acceleration can reach $1.7 \mathrm{~g}$, and the loading frequency range is $0.1-70 \mathrm{~Hz}$. A rigid model box is used in the test, and the box size is $2.8 \mathrm{~m} \times 1.4 \mathrm{~m} \times 1.2 \mathrm{~m}$ (Figure 2).

3.2. Similar Design. Considering that the three model tests are all simulation tests of loess slope failure under the action of seismic ground motion, due to the mechanical properties of loess which is easy to be damaged under dynamic action, the similarity of elastic restoring force is not emphasized in the similar design, but the similarity conditions of gravity and resistance are mainly considered [32]. Therefore, the similarity ratio of cohesion and density is determined as the main control quantity. Loess is a kind of soil with microstructure, and particle composition is one of the elements of its microstructure. Therefore, remolded loess is used as the model material, so the model soil would have certain microstructure and structural strength [18]. Through a large number of proportioning laboratory tests loess with different water content and dynamic triaxial shear tests of the remolded loess sample, except that the cohesion $c$ value is $9 \mathrm{kPa}$, it is not within the target value range of $4.3-5.0 \mathrm{kPa}$ (Table 1), and other material parameters are within the target value range.

3.3. Model Making. The making process of the model strictly follows the fixed process shown in Figure 3. First, the undisturbed loess is crushed, sieved by $0.5 \mathrm{~mm}$, and then mixed 


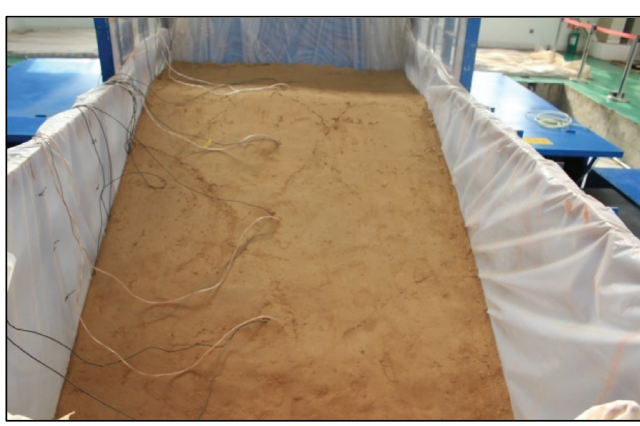

(a)

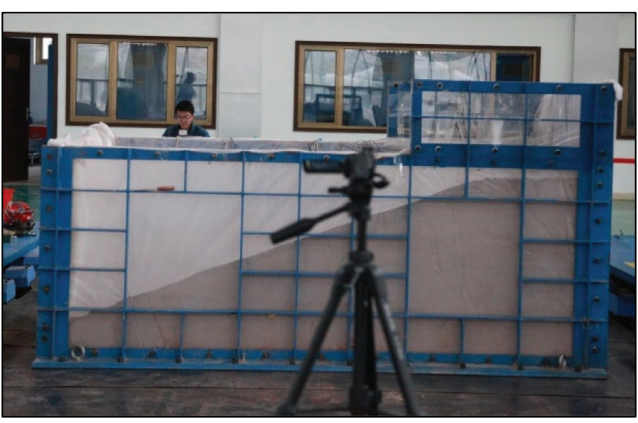

(b)

Figure 2: Shaking table slope model. (a) Front view. (b) Side view.

TABLE 1: Similarity relationship.

\begin{tabular}{|c|c|c|c|c|c|c|}
\hline Physical quantity & $\begin{array}{l}\text { Similarity } \\
\text { relationship }\end{array}$ & $\begin{array}{c}\text { Similarity } \\
\text { ratio }\end{array}$ & Prototype soil & $\begin{array}{l}\text { Target value of } \\
\text { model soil }\end{array}$ & Model soil & Remark \\
\hline Geometrical size $(\mathrm{m})$ & $S_{L}=10$ & 10 & & & & Control parameter \\
\hline Density $\left(\mathrm{kg} / \mathrm{m}^{3}\right)$ & $S_{\rho}=1$ & 1 & $1.21-1.42$ & $1.30-1.40$ & 1.32 & Control parameter \\
\hline Cohesion $(\mathrm{kPa})$ & $S_{c}=S_{L} S_{\rho}$ & 10 & $26-50.3$ & $4.3-5.0$ & 9 & \\
\hline Inner friction angle $\left({ }^{\circ}\right)$ & $S_{\varphi}=1$ & 1 & $21-33$ & $21-33$ & 31 & \\
\hline Water content $(\%)$ & $S_{w}=1$ & 1 & $4.1-6.5$ & $4.1-6.5$ & 6.3 & Control parameter \\
\hline Poisson's ratio & $S_{\mu}=1$ & 1 & & & & \\
\hline Acceleration $\left(\mathrm{m} / \mathrm{s}^{2}\right)$ & $S_{a}^{r}=1$ & 1 & & & & \\
\hline
\end{tabular}

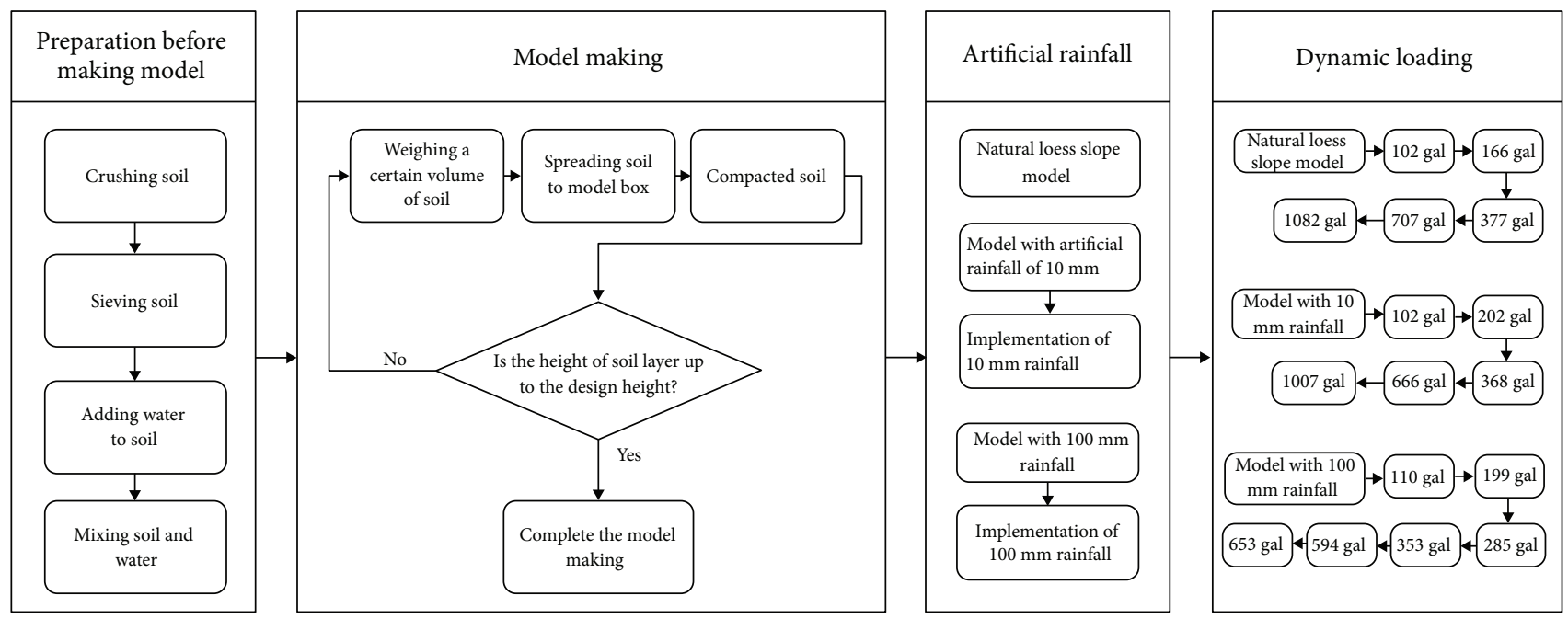

FIGURE 3: Flowchart of the shaking table model test.

with water. According to the soil volume of each layer of $10 \mathrm{~cm}$ height, it is weighed and evenly spread in the model box. Then, it is compacted with steel plate, and the model is made layer by layer until the design height of the model is reached. In the process of making the model, sensors of acceleration, earth pressure, and pore pressure are set up, and the position of sensors and model size are shown in Figure 4.

3.4. Rainfall Implementation. A self-designed artificial rainfall equipment was built to simulate the rainfall process in the Loess Plateau. Two main yellow hoses were used to transport water and air, respectively [33]. Five injectors are deployed equidistantly, and rainwater could be sprayed evenly on slope surface. The intensity of the rain could be controlled by five valves. The rainfall intensity is adjustable in the range of $5-100 \mathrm{~mm}$, which would realize various rainfall conditions from light rain to heavy rain in the Loess Plateau.

After the model making was completed, the natural loess slope model was immediately hoisted to the shaking table for vibration tests under various loading conditions. For the loess slope model with rainfall of $10 \mathrm{~mm}$, artificial rainfall with a 


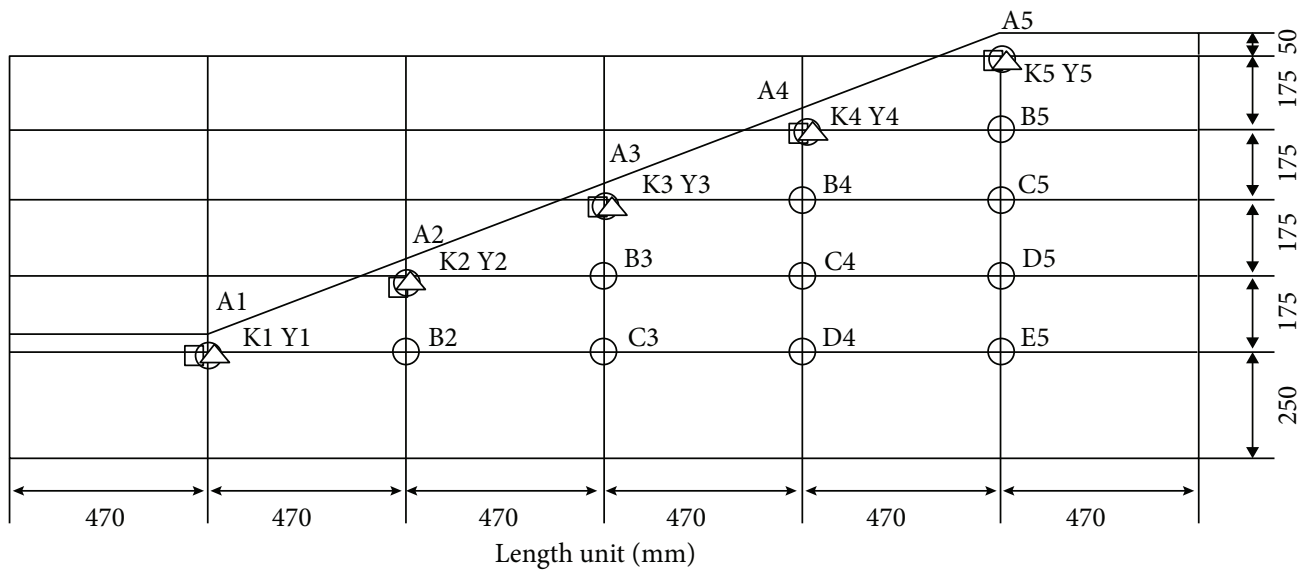

$\triangle$ Pore pressure sensor
$\square$ Soil pressure sensor
$\bigcirc$ Acceleration sensor

Figure 4: Slope model size and sensor location.

rainfall intensity of $10 \mathrm{~mm} / \mathrm{h}$ and a total rainfall of $10 \mathrm{~mm}$ was simulated by a self-made rainfall device, and the model test under various working conditions was carried out about 30 minutes after rainfall. For the loess slope model with rainfall of $100 \mathrm{~mm}$, artificial rainfall with a rainfall intensity of $20-30 \mathrm{~mm} / \mathrm{h}$ and a total rainfall of $100 \mathrm{~mm}$ was simulated by a self-made rainfall device, the artificial rainfall process lasted about four hours, and the model test under various working conditions was carried out about 30 minutes after the rainfall.

3.5. Loading Mode. In order to compare and analyze model tests under three kinds of rainfall condition, the horizontal acceleration time history recorded by Minxian seismic station of the Minxian-Zhangxian Ms 6.6 earthquake in 2013 was loaded in the tests (Figure 5), and the input amplitude values under different loading conditions were modulated as needed. The slope model test of natural state $(0 \mathrm{~mm})$ was loaded with $102 \mathrm{gal}, 166 \mathrm{gal}, 377 \mathrm{gal}, 707 \mathrm{gal}$, and $1082 \mathrm{gal}$ Minxian waves. The slope model test with $10 \mathrm{~mm}$ rainfall was loaded with $102 \mathrm{gal}, 202 \mathrm{gal}, 368 \mathrm{gal}, 666 \mathrm{gal}$, and 1007 gal Minxian waves. The slope model test with $100 \mathrm{~mm}$ rainfall was loaded with $110 \mathrm{gal}, 199 \mathrm{gal}, 285 \mathrm{gal}, 353 \mathrm{gal}$, $594 \mathrm{gal}$, and 653 gal Minxian waves.

\section{Analysis of Test Results}

\subsection{Macrodamage}

4.1.1. The Natural Loess Slope Model Test. At 377 gal, small tensile fissures begin to appear at the slope shoulder; at 707 gal (Figure 6(a)), the small fissures expand into larger cracks and the opening increases; at 1082 gal (Figure 6(b)), there is a through crack at the front edge of the slope top and about $10 \mathrm{~cm}$ near the slope shoulder, with a depth of about $60 \mathrm{~cm}$ and a maximum opening of about $2-4 \mathrm{~cm}$. There are many secondary cracks in the front and back of the main crack and the lower edge of the slope shoulder, which indicate that the slope model is instability.
4.1.2. The Slope Model Test with $10 \mathrm{~mm}$ Rainfall. At $368 \mathrm{gal}$, several tensile cracks appear on the top of the slope, and the maximum opening is about $3-5 \mathrm{~mm}$. At $666 \mathrm{gal}$ (Figure 6(c)), the soil at the top of the slope was seriously damaged, the seismic subsidence of the soil is about $2 \mathrm{~cm}$, and the front edge of the slope appeared stepped sliding with the maximum slip of $2 \mathrm{~cm}$. At 1007 gal (Figure 6(d)), the total amount of seismic subsidence on the top of the slope is $5 \mathrm{~cm}$, the sliding range and sliding amount of the slope shoulder increase, and the maximum sliding is $5 \mathrm{~cm}$. Several through tensile cracks are appeared on the slope shoulder and its adjacent area, with the opening of about $1-2 \mathrm{~cm}$ and the deepest of $30-40 \mathrm{~cm}$. The cracks are all over the top of the slope and the upper and middle parts of the slope, which indicates the instability of the slope.

4.1.3. The Slope Model Test with $100 \mathrm{~mm}$ Rainfall. At 353 gal, the middle part of the slope top subsided about $1-2 \mathrm{~cm}$, and the middle part of the slope shoulder slipped about $3 \mathrm{~cm}$. At $594 \mathrm{gal}$ (Figure 6(e)), the external shape of the slope changed greatly, and significant soil seismic subsidence and liquefaction slip phenomena appeared. There is a large area of seismic subsidence about $5 \mathrm{~cm}$ in the middle part of the slope top, and the liquefaction slip of the slope shoulder is about $9 \mathrm{~cm}$. At $653 \mathrm{gal}$ (Figure 6(f)), the sliding soil mass slided about $20 \mathrm{~cm}$.

\subsection{Variation of Dynamic Parameters of the Slope Model}

4.2.1. Calculation Method. The transfer function is the expression of dynamic characteristics of the vibration system in frequency domain. The dynamic parameters of the slope model can be calculated by the relative acceleration transfer function of a certain part in the slope model test [34]. The transfer function is expressed by the following formula:

$$
T_{a}\left(\omega, z_{j}\right)=\frac{G_{x y}\left(\omega, z_{j}\right)}{G_{x x}(\omega)},
$$




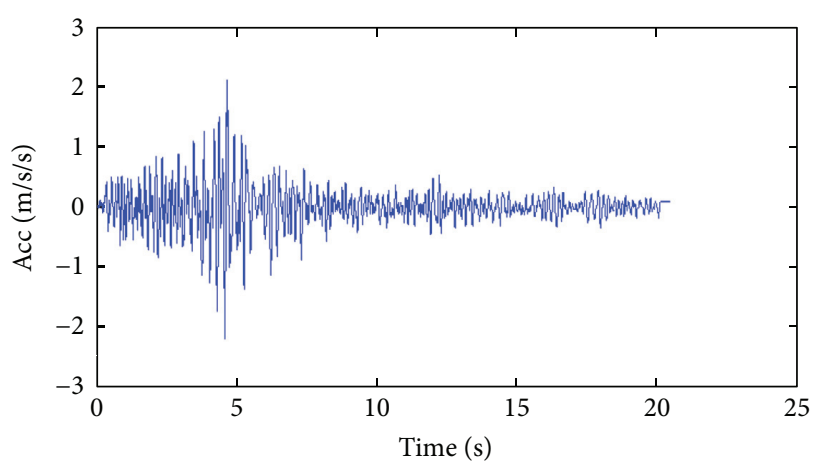

(a)

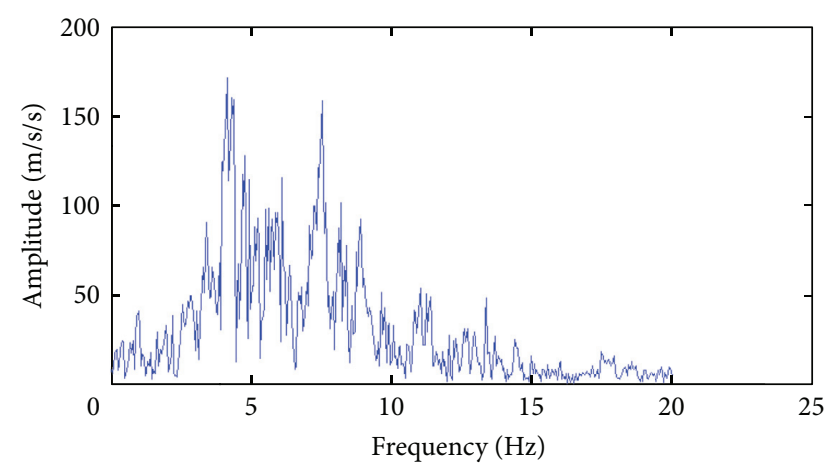

(b)

FIGURE 5: Time history and frequency spectrum of Minxian seismic wave loaded. (a) History time. (b) Fourier spectrum.
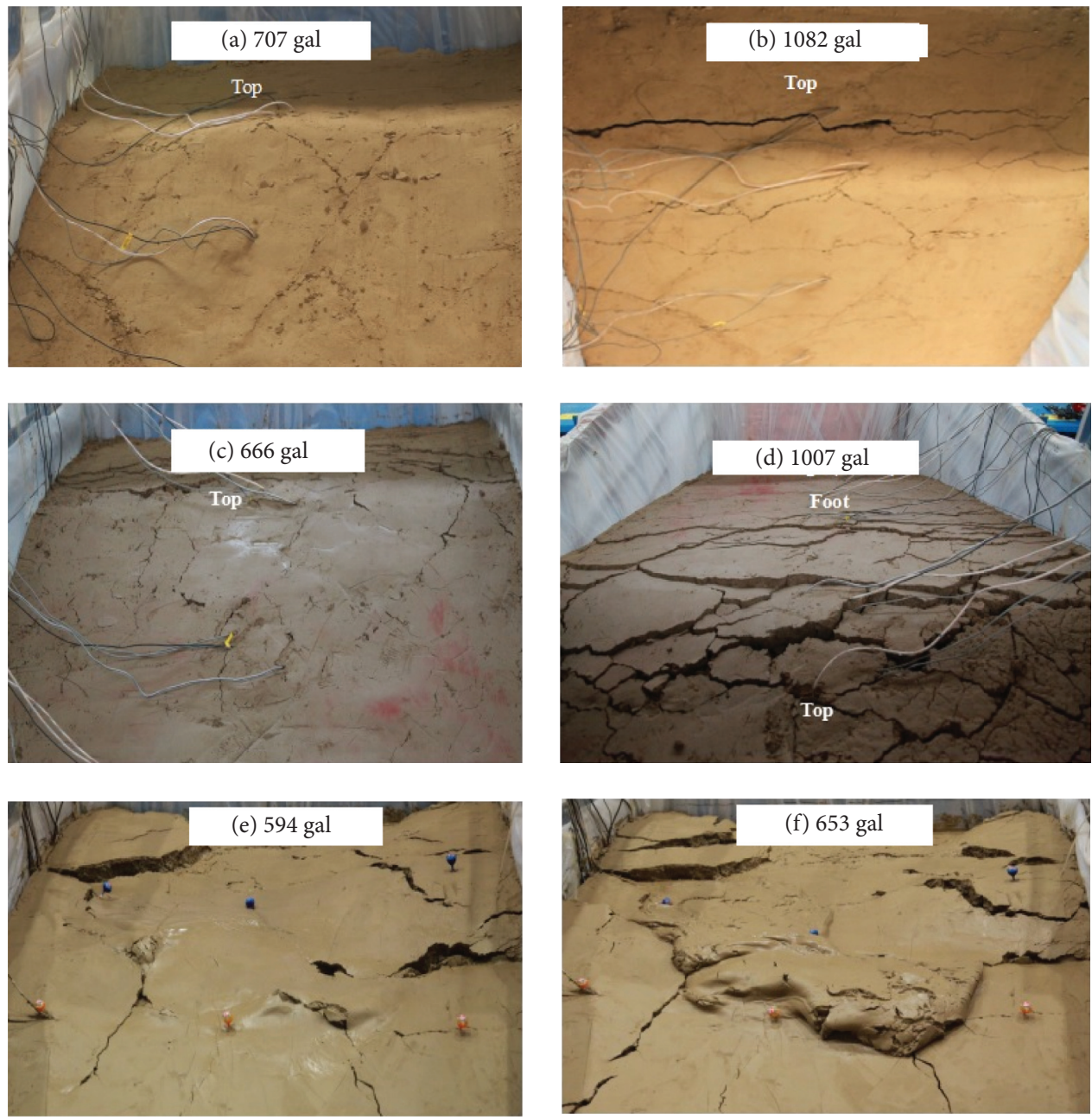

Figure 6: Macroscopic failure phenomenon of the slope model. (a)-(b) Natural state; (c)-(d) $10 \mathrm{~mm}$ rainfall; (e)-(f) $100 \mathrm{~mm}$ rainfall.

where $G_{x x}$ is the autocorrelation function of input, $G_{x y}$ is the cross-correlation function of input and response, $\omega$ is the circular frequency of input wave, and $z_{j}$ is the coordinate function of response part. The frequency of the peak value in the spectrum curve of the transfer function is the first-order natural frequency of the $j$ point of the slope model, and the damping ratio of point $j$ is

$$
\lambda=\frac{f_{2}-f_{1}}{2 f_{0}},
$$

where $f_{0}$ is the frequency of the peak value, and $f_{1}, f_{2}$ are the two frequencies corresponding to 0.707 times of the peak value. The shaking table test shows that the peak value, frequency, and damping ratio of the first-order vibration 
mode of slope shoulder decrease regularly with the increase of dynamic loading intensity $[20,21]$. Therefore, the peak value, frequency, and damping ratio of the first-order mode of the relative acceleration transfer function (TF) of the slope shoulder under different loading conditions are used to analyze the slope model stability.

The shaking table test can also directly show the amplification effect of peak ground acceleration (PGA) [21, 22], so the PGA amplification effect is also included into the scope of the slope model, stability analysis. In this study, the ratio of the peak value of input acceleration $A_{\text {umax }}$ to the peak value of response acceleration $A_{\text {smax }}$ is defined as the dynamic response coefficient, that is $A_{P G A}$, which is expressed as follows:

$$
A_{\mathrm{PGA}}=\frac{A_{\mathrm{smax}}}{A_{\mathrm{umax}}} .
$$

4.2.2. Variation of Dynamic Parameters of the Loess Slope Model. The macroscopic failure phenomena of the slope model under three rainfall conditions mainly occur in the shoulder and its adjacent areas, and these areas are also the most significant parts of the amplification effect of seismic ground motion. Therefore, the change of the frequency spectrum curve of the transfer function (TF) at the slope shoulder with loading intensity can well reflect the process information of the dynamic instability of the slope model. With the increase of loading intensity, the peak value and shape of TF spectrum curve of relative acceleration at A5 point of slope shoulder of the slope model change regularly (Figure 7). Therefore, its amplitude, first-order frequency, and damping ratio are extracted and calculated for analysis.

It can be seen from Figure 7 that the peak value of the TF frequency spectrum curve under different rainfall conditions decreases regularly with the increase of dynamic loading intensity. Through polynomial fitting, the following three formulas can be obtained:

$$
\begin{aligned}
A_{\mathrm{TF} 100} & =-22.25 a^{2}-12.23 a+12.45, \\
A_{\mathrm{TF} 10} & =-8.51 a^{2}-5 a+10.57, \\
A_{\mathrm{TF} 0} & =-6.48 a^{2}-0.74 a+7.78 .
\end{aligned}
$$

In the above formulas, $A_{\mathrm{TF} 100}, A_{\mathrm{TF} 10}$, and $A_{\mathrm{TF} 0}$ are the peak values of the TF spectrum curve of slope shoulder for rainfall model tests of $100 \mathrm{~mm}, 10 \mathrm{~mm}$, and $0 \mathrm{~mm}$, respectively, and a is the input seismic acceleration.

As shown in Figure 8, after the slope model under different rainfall conditions is unstable and damaged, the TF spectrum curve of the slope shoulder is dispersive, without an obvious peak value, and the curve amplitude fluctuates around 2. Due to the large dispersion of the input acceleration between different loading conditions in the test, the critical acceleration of slope instability cannot be accurately obtained. Therefore, taking 2 as the critical value of TF spectrum amplitude during slope instability [21, 22], through formulas (4)-(6), it can be calculated that the peak values of seismic critical instability acceleration under rainfall of $100 \mathrm{~mm}, 10 \mathrm{~mm}$, and natural state are $0.463 \mathrm{~g}$, $0.746 \mathrm{~g}$, and $0.889 \mathrm{~g}$, which is more scientific and reasonable than the critical instability acceleration values of 594 gal, $1007 \mathrm{gal}$, and $1082 \mathrm{gal}$, roughly obtained from loading conditions through the macrofailure phenomenon.

As shown in Figure 7(b), when the dynamic loading intensity is low, the first-order natural frequency of the slope model decreases linearly. With the increase of dynamic loading intensity, the natural frequency would decrease rapidly and nonlinearly, and the change process of natural frequency under different rainfall conditions can be expressed by the following fitting formulas:

$$
\begin{aligned}
f_{100} & =-32.5 a^{2}+0.75 a+23.73, \\
f_{10} & =-18.94 a^{2}+1.14 a+27.29, \\
f_{0} & =-19.51 a^{2}+3.09 a+31.15 .
\end{aligned}
$$

In the above formulas, $f$ is the natural frequency of the slope model under different rainfall conditions, subscript is the rainfall, and $a$ is the acceleration.

The dynamic damping ratio increases with the increase of loading intensity (Figure $7(\mathrm{c})$ ), which reflects the physical process that with the increase of dynamic loading intensity, the soil damage on the top of slope is intensified and accumulated under the action of dynamic shear stress, and the energy dissipation of soil is significantly enhanced. The change process of damping ratio under different rainfall conditions can be expressed by the following polynomial fitting formula:

$$
\begin{aligned}
\lambda_{100} & =1.25 a^{2}-0.155 a+0.26, \\
\lambda_{10} & =0.33 a^{2}+0.17 a+0.18, \\
\lambda_{0} & =0.12 a^{2}+0.21 a+0.1 .
\end{aligned}
$$

In the above formulas, $\lambda$ the damping ratio of slope model soil under different rainfall conditions, subscript is the rainfall, and $a$ is the acceleration.

Before the failure of the slope model, the amplification factor of PGA at the top of slope increases with the increase of dynamic loading; after the failure, the amplification factor decreases significantly (Figure 7(d)). The test results of three rainfall conditions are similar.

\section{Slope Stability Evaluation Based on Shaking Table Test Results}

5.1. Calculation Method of Seismic Instability Critical Acceleration of Prototype Slope. According to the viewpoint of similar behavior in the shaking table model test, in order to ensure similar deformation and failure, the acceleration amplitude must meet the following similar conditions [35]:

$$
S_{a}=S_{[\tau]} S_{\rho}^{-2 / n} S_{L}^{-1},
$$

where $S$ is the similarity ratio, and subscripts $a,[\tau], \rho$, and $L$ represent acceleration, shear strength, density, and 


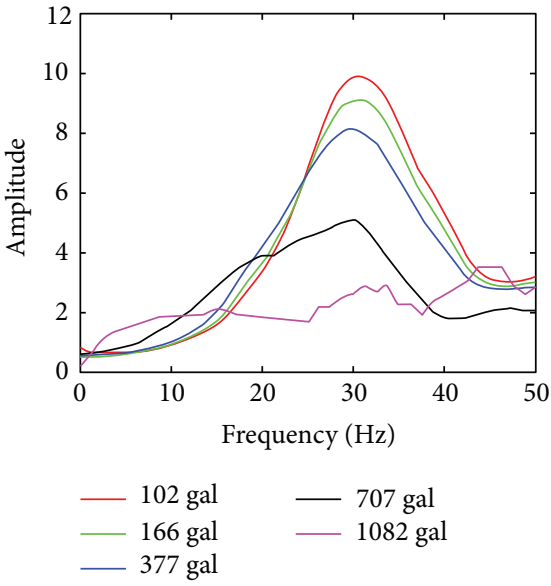

(a)

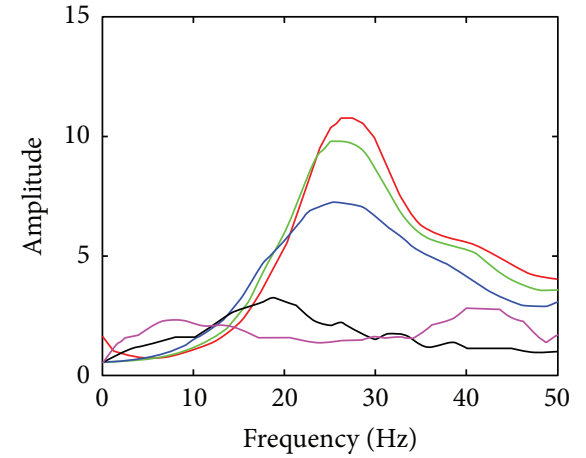

$-102 \mathrm{gal} \quad-666 \mathrm{gal}$
$-202 \mathrm{gal} \quad 1007 \mathrm{gal}$
$-368 \mathrm{gal}$

(b)

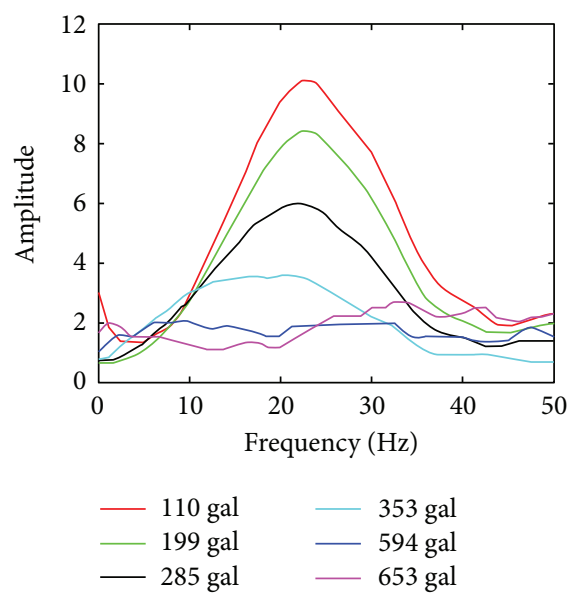

(c)

Figure 7: TF spectrum curve at A5 point of slope shoulder of the slope model. (a) Transfer function spectrum (0 mm). (b) Transfer function spectrum $(10 \mathrm{~mm})$. (c) Transfer function spectrum $(100 \mathrm{~mm})$.
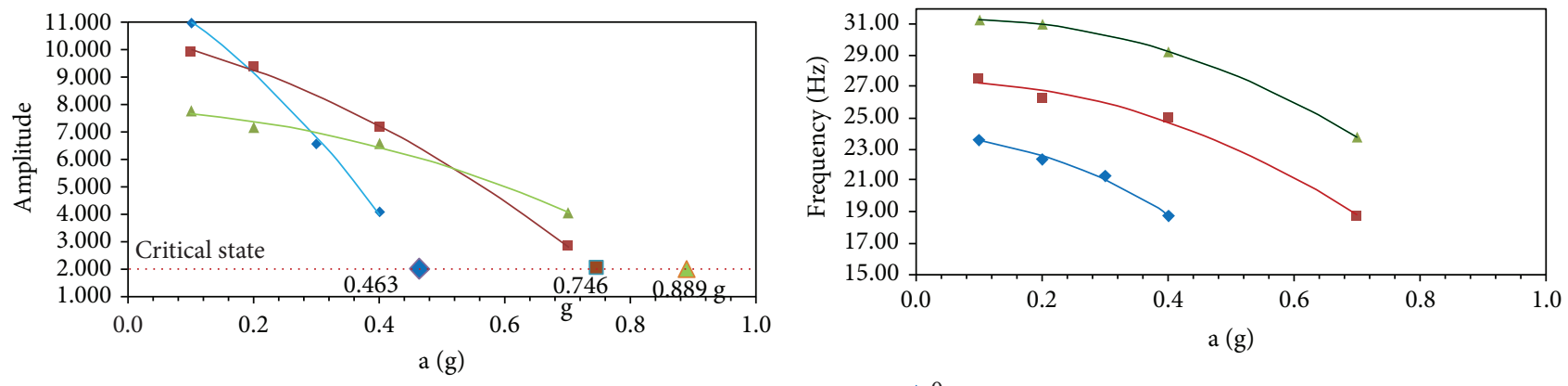

- $0 \mathrm{~mm}$

$\bullet 0 \mathrm{~mm}$

- $10 \mathrm{~mm}$

- $10 \mathrm{~mm}$

4 $100 \mathrm{~mm}$

(a)

(b)

Figure 8: Continued. 


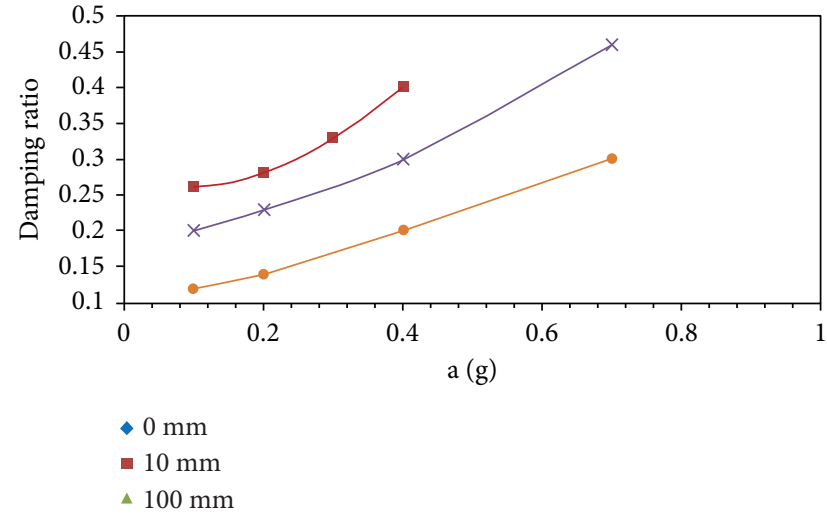

(c)

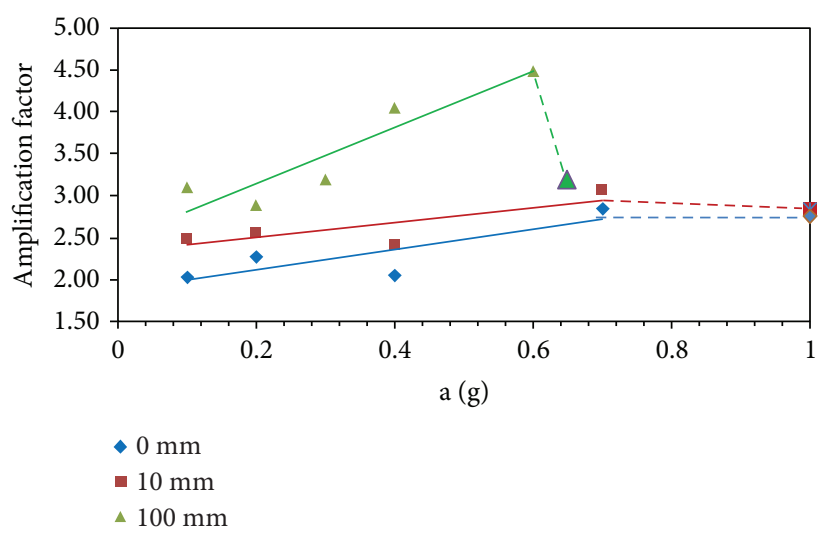

(d)

Figure 8: Variation of several parameters at A5 with dynamic loading intensity. (a) Peak value of transfer function spectrum. (b) Natural frequency. (c) Damping ratio. (d) Amplification factor.

geometric size, respectively. In the process of seismic dynamic action, the soil mass of slope is in the combined state of self-weight stress and dynamic shear stress, and the horizontal shear strength of the soil element is controlled by the Mohr-Coulomb criterion:

$$
[\tau]=\sqrt{\left[\frac{1+k_{0}}{2} \sigma_{v} \sin \varphi+c \cos \varphi\right]^{2}+\left[\frac{1-k_{0}}{2} \sigma_{v}\right]^{2}}
$$

where $\sigma_{v}$ is the normal compressive stress, $\varphi$ is the internal friction angle of soil, $c$ is the cohesion of soil, and $k_{0}$ is the lateral pressure coefficient. Through formula (10), the shear strength of the top and bottom surfaces of the prototype and model of the slope is calculated, and the average is taken as the ultimate shear strength $[\tau]$.

Based on the above calculation method, $S_{[\tau]}$ calculated from the related parameters in Table 1 is 6.56 , and $S_{a}$ calculated from equation (9) is 0.656 . The critical instability acceleration of the prototype slope is converted from the critical instability acceleration of the slope model, which should be multiplied by similarity ratio $S_{a}$. Therefore, under the condition of rainfall of $100 \mathrm{~mm}, 10 \mathrm{~mm}$, and $0 \mathrm{~mm}$, the critical acceleration of seismic instability of the prototype slope should be 304 gal, 489 gal, and 581 gal, which indicates that for low loess slope with a slope of $20^{\circ}$, the slope instability would occur under the action of seismic ground motion equivalent to 8 degrees of seismic intensity after heavy rain, while the slope instability would occur under the action of seismic ground motion equivalent to 9 degrees of seismic intensity after light rain or no rainfall. This result is basically consistent with actual failure cases of slopes under earthquake.

\subsection{Calculation Method of Stability Factor Based on the} Shaking Table Test. The critical acceleration of slope instability could be obtained in the shaking table test, but a quantitative result for the slope stability could not be obtained under the action of seismic ground motion below the critical acceleration, and which is not convenient to compare with the stability factor is calculated by the traditional limit equilibrium method and the finite element strength reduction method, which bring a lot of inconvenience to the application of the shaking table model test results in the seismic design of slope.

The shaking table test results of slope under three kinds of rainfall conditions show that the strongest part of the PGA amplification effect is in the slope shoulder area, which is also the area where the soil damage is the most serious and the slope model is the first to failure. The transfer function could reflect the internal dynamic characteristics of system, and the first-order natural frequency and its corresponding peak value and damping ratio calculated by the relative acceleration transfer function of the slope shoulder would increase or decrease with increase of dynamic loading strength, which reveals the physical change process of slope from soil damage generation to continuous accumulation and then to slope failure. Therefore, the changes of the above parameters can reflect the deformation evolution and failure process of slope.

In the slope model test, the acceleration time history is relatively accurate, reliable, and easy to measure. Through the spectrum analysis of the acceleration transfer function, the first-order natural frequency and damping ratio of the slope model can be obtained. Based on macroscopic damage phenomenon of the slope model and the curve of spectrum peak value of the transfer function changing with dynamic loading strength, the critical instability acceleration $a_{\text {cr }}$ can be obtained. By substituting $a_{\mathrm{cr}}$ into the fitting formula of the spectrum peak value of TF and the first-order frequency changing with loading strength, the first-order natural frequency $f_{\text {cr }}$ and the damping ratio $\lambda_{\text {cr }}$ of the slope model in the critical instability state can be obtained. Because the natural frequency $f$ of slope has the following relationship with the shear wave velocity vs. of slope soil layer,

$$
f=\frac{V_{s}}{4 H},
$$




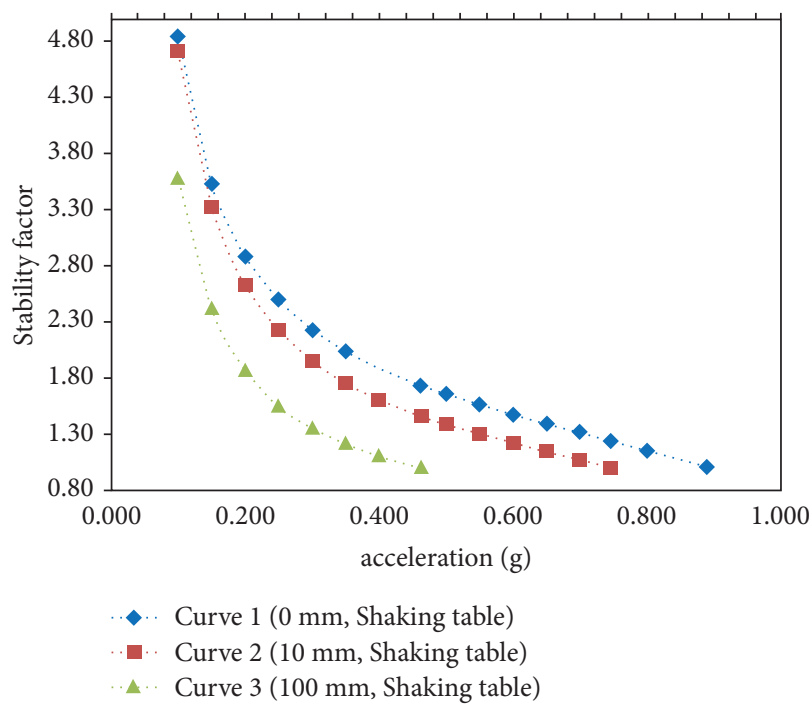

(a)

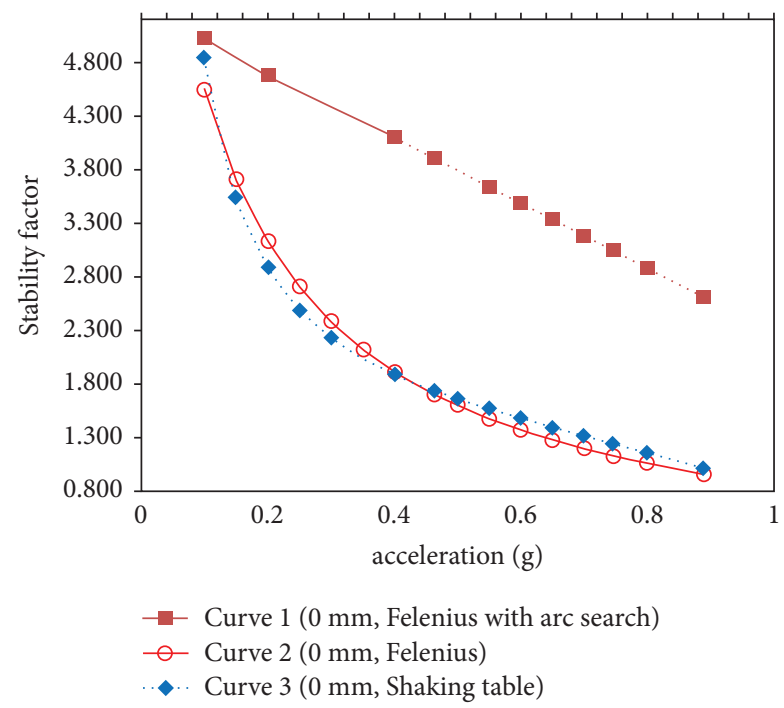

(b)

FIGURE 9: Slope stability factors calculated by different methods. (a) Stability factors with three rainfalls based on the shaking table test. (b) Stability factors calculated by different methods.

where $H$ is the slope height, so the shear wave velocity of slope soil layer can be calculated according to the natural frequency of slope. There is a positive correlation between shear wave velocity and shear strength of soil [22], and the normalized product of $V_{\mathrm{si}} / V_{\mathrm{scr}}$ and $\lambda_{i} / \lambda_{\mathrm{cr}}$ is used to represent the strength reserve of soil; $a_{i} / a_{\mathrm{cr}}$ is used to represent sliding force, so the slope stability factor $F_{\mathrm{ds}}$ under seismic action can be expressed by the following formula:

$$
F_{\mathrm{ds}}=\frac{\left(V_{\mathrm{si}} / V_{\mathrm{scr}}\right) \times\left(D_{i} / D_{\mathrm{cr}}\right)}{\left(a_{i} / a_{\mathrm{cr}}\right)} .
$$

Based on the calculated results of relevant physical quantities of the shaking table test, through the shaking table test results, the stability of the prototype loess slope can be quantitatively predicted and evaluated. As shown in Figure 9 , the stability factor of loess slope under different rainfall conditions decrease nonlinearly with the increase of loading (Figure 9(a)), which accord with the basic laws of physical mechanics.

The Fellenius method, which is one of the limit equilibrium methods, is used to calculate the stability factor of natural loess slope $(0 \mathrm{~mm})$ under seismic ground motion, and the results calculated by this method are compared with those calculated by formula (12). As shown in Figure 9(b), there are some differences between the results calculated by formula (12) (curve 3) and those calculated by Fellenius (curvel and curve 2), and there are also significant differences between curve 1 and curve 3, while there is a slight difference between curve 2 and curve 3 . Curve 1 calculated based on the potential sliding surface (Figure 10(b)) searched by the automatic arc search method of Fellenius decreases linearly with the increase of loading, the solid line of curve 1 is calculated based on Lizheng geotechnical software (a software developed by Lizheng software company in China), and the dotted part is drawn according to the fitting formula of the solid part. Curve 2 is calculated by the Fellenius method based on the potential sliding surface ( $L_{\text {down }}, L_{\text {mid }}$, and $L_{\text {up }}$ in Figure $10(\mathrm{a})$ ) in the shaking table slope model test, which refers to the results of our previous shaking table test [20], the stability factors (curve 2) and formula (12) decrease nonlinearly with the increase of seismic ground motion intensity, and the results of the two methods are very close. This shows that it is basically practicable to apply formula (12) to evaluate the slope stability based on the results of the shaking table slope model test. As for the difference of the slope stability factor caused by different potential sliding surfaces of the Fellenius method, it is not in the scope of this research, so it is not discussed much. For the loess slope with rainfall of $10 \mathrm{~mm}$ and $100 \mathrm{~mm}$, the failure under earthquake involves the complex mechanical mechanism [21, 22], so the Fellenius method is not used to calculate the stability factor of the slope for comparative analysis.

\section{Discussion}

In the loess slope model test, if the loess of prototype site is used as the model material, the condition of similar microstructure would be satisfied to a certain extent. Under the action of seismic ground motion, the seismic wave in the slope model propagates in the form of stress wave from bottom to top. The microstructure of slope soil continues to damage, the dynamic residual deformation gradually occurs and accumulates, and the mechanical properties of soil continue to deteriorate. When the dynamic loading reaches a certain degree, the slope model would lose stability and failure. The peak value of transfer function spectrum, the natural frequency of slope, and the damping of soil mass could reflect the process from soil damage to slope instability, so the stability factor $F_{\mathrm{ds}}$ based on these parameters could reflect the degree of slope stability under seismic 


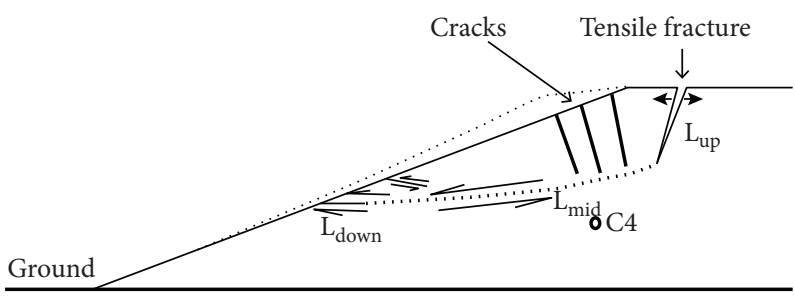

(a)

Figure 10: Potential sliding surface of slope in different methods. (a) Potential sliding surface (shaking table test). (b) Sliding surface of automatic search (Fellenius).

dynamic action. The calculation method of slope stability factor $F_{\mathrm{ds}}$ mainly refers to the idea of calculating the stability factor of slope by the strength reduction method of finite element, and the theoretical basis of this method is different from that of the traditional limit equilibrium method, so the calculation results of the two methods would have some differences. However, if the potential sliding surface obtained from the shaking table test is used to calculate the slope stability factor by limit equilibrium, the two results are very similar; this shows that the calculation method of stability factor $F_{\mathrm{ds}}$ based on the shaking table test is practicable. For the important slope engineering, it is suggested that the results of the shaking table test and other methods should be combined to evaluate the seismic stability of the slope, so as to get more reliable conclusions. But, the calculation method proposed in this study based on the shaking table model test is a simplified calculation method based on the premise that the slope stability factor in critical state is 1 , so the method needs to be further verified and improved by engineering practice, so as to make the costly shaking table model test better serve the geotechnical earthquake engineering, disaster prevention, and other works.

\section{Conclusion}

(1) In the shaking table model test of slope, the peak value of TF spectrum, natural frequency of slope, and damping ratio of soil would change regularly with the increase of loading intensity. Therefore, the fitting polynomial formula of these variables with seismic ground motion intensity could be obtained. Referring to the macroscopic failure phenomenon and related instability criteria of the shaking table test, the acceleration of critical instability of slope could be accurately determined; the first-order natural frequency of slope and damping ratio of soil mass under the action of any seismic ground motion which is less than the critical instability acceleration could be calculated accurately based on the fitting formula.

(2) For the model test, loess slope failure is because of the low cohesive strength of loess, which is difficult to meet the requirements of similar design. When the cohesive strength of soil is greater than the design target value, higher loading intensity is needed to achieve the stress state requirements of similar behavior failure of the prototype and model. Therefore, based on the behavior similarity theory of the shaking table model test, the reduction method of applying the critical instability acceleration obtained from the model test to prototype slope is proposed when the cohesion of model soil does not meet the requirement of similarity ratio, which provides a practicable way for predicting the critical instability acceleration of loess slope under the action of seismic ground motion.

(3) Considering the actual failure behavior of loess slope models under three rainfall conditions, based on the model dynamic parameters extracted from the TF spectrum curve, a calculation method of loess slope stability factor $F_{\mathrm{ds}}$ value based on the shaking table model test is proposed, which can be used to predict the stability state of loess slope under different intensities of seismic ground motion and provides a reference way for seismic design of loess slope. The calculation method of the loess slope stability factor based on the shaking table model test proposed in this manuscript still needs to be testified in practice and further improved, so that the expensive shaking table model test can better serve the work of geotechnical earthquake engineering and disaster prevention.

\section{Data Availability}

The data used to support the findings of this study are included within the article.

\section{Conflicts of Interest}

The authors declare that they have no conflicts of interest.

\section{Acknowledgments}

This study was supported by the National Natural Science Foundation of China (U1939209), Basic Scientific Research Fund and Science and Technology Innovation Base of Lanzhou, Institute of Earthquake Forecasting, China Earthquake Administration (2021IESLZ02 and 2018 IESLZ07), and Key Research and Development Projects of Gansu Province (18YF1FA101). Dr. Zh. Wu, Mr. Q. Wang, 
Mr. H. Guo, and Ms. J. Ma are appreciated for their assistance during the tests.

\section{References}

[1] L. Wang and J. Sun, "Seismic safety issues in the process of urban development in Loess Plateau," Earthquake Engineering and Engineering Dynamics, vol. 34, no. 4, pp. 115-122, 2014.

[2] X. Pu, L. Wang, and $\mathrm{Z}$. Wu, "Engineering geological problems of loess high excavation slope of loess hilly and gully region of Lanzhou and its stability analysis," China Earthquake Engineering Journal, vol. 38, no. 5, pp. 787-794, 2016.

[3] Standardization Administration of China, Seismic Ground Motion Parameters Zonation Map of China (GB18306-2015), Standardization Administration of China, Beijing, China, 2015.

[4] L. Wang, Loess Dynamics, Earthquake Press, Beijing, China, 1st edition, 2003.

[5] Y. Chen and Y. Shi, "Characteristics of seismic landslide in loess area of northwest China," Seismic Research, vol. 3, pp. 276-280, 2006.

[6] L. Deng and W. Fan, "Study on deformation and failure mechanism and development mechanism of loess landslide induced by magnitude 8.5 earthquake in Ningxia," Journal of Disasters, vol. 3, pp. 30-37, 2013.

[7] L. Wang, Z. Yuan, and Y. Shi, "Study on index and method of seismic disaster division in loess plateau," Journal of Natural Disasters, vol. 3, pp. 87-92, 1999.

[8] N. Snithhan and W. F. Chen, "Finite element analysis of large deformations in slopes," in Proceedings of the Conf. Numer. Meth, vol. 21, pp. 744-756, In Geotech, Blacksburg, VA, USA, 1997.

[9] Y. Kohgo and T. Yamashita, "Finite element analysis of fill type dams-stability during construction by using the effective stress concept," Journal of the Soil Mechanics and Foundations Division, vol. 124, no. 7, pp. 653-665, 1998.

[10] D. V. Griffiths and P. A. Lane, "Slope stability analysis by finite elements," Géotechnique, vol. 49, no. 3, pp. 387-403, 1999.

[11] E. M. Dawson, W. H. Roth, and A. Drescher, "Slope stability analysis by strength reduction," Géotechnique, vol. 49, no. 6 , pp. 835-840, 1999.

[12] H. Nguyen-Xuan, G. R. Liu, S. Bordas, S. Natarajan, and T. Rabczuk, "An adaptive singular ES-FEM for mechanics problems with singular field of arbitrary order," Computer Methods in Applied Mechanics and Engineering, vol. 253, pp. 252-273, 2013.

[13] H. Nguyen-Xuan, C. T. Wu, and G. R. Liu, "An adaptive selective ES-FEM for plastic collapse analysis," European Journal of Mechanics A/Solids, vol. 58, Article ID 278e290, 2016.

[14] T. N. Nguyen, T. D. Ngo, and H. Nguyen-Xuan, "A novel three-variable shear deformation plate formulation: theory isogeometric implementation," Computer Methods in Applied Mechanics and Engineering, vol. 326, pp. 376-401, 2017.

[15] T. Miao, Z. Liu, and J. Ren, "Deformation mechanism and constitutive relation of collapsible loess," Chinese Journal of Geotechnical Engineering, vol. 21, no. 4, pp. 783-787, 1999.

[16] G. Gao, "Classification of loess microstructure and collapsibility," Science of China, no. 12, pp. 1203-1208, 1980.

[17] D. Xie and J. Qi, "Soil structure characteristics and research on its quantitative parameter," Chinese Journal of Rock Mechanics and Engineering, vol. 16, no. 4, pp. 651-656, 1999.
[18] S. Shao, F. Zhou, and J. Long, "Structural properties of loess and its quantitative parameter," Chinese Journal of Geotechnical Engineering, vol. 26, no. 4, pp. 531-536, 2004.

[19] C. D. F. Rogers, T. A. Dijkstra, and I. J. Smalley, "Hydroconsolidation and subsidence of loess: studies from China, Russia, North America and Europe," Engineering Geology, vol. 37, no. 2, pp. 83-113, 1994.

[20] X. Pu, L. Wang, and P. Wang, "Study of shaking table test on dynamic response characteristics and failure mechanism of the loess slope," Earthquake Research in China, vol. 34, no. 1, pp. 121-135, 2020.

[21] X. Pu, L. Wang, P. Wang, and S. Chai, "Study of shaking table test of seismic subsidence loess landslides induced by the coupling effect of earthquakes and rainfall," Natural Hazards, vol. 103, no. 1, pp. 923-945, 2020.

[22] X. Pu, L. Wan, and P. Wang, "Initiation mechanism of mudflow-like loess landslide induced by the combined effect of earthquakes and rainfall," Natural Hazards, vol. 105, no. 3, pp. 3079-3097, 2021.

[23] L. Wang, X. Pu, and $\mathrm{Z}$. Wu, "Shaking table test on dynamic response of loess slope under coupling action of earthquake and rainfall," Journal of Geotechnical Engineering, vol. 40, no. 7, pp. 1287-1293, 2018.

[24] L. Wang, X. Pu, and Z. Wu, "Shaking table test of loess slope instability and sliding under the coupling effect of earthquake and rainfall," Journal of Rock Mechanics and Engineering, vol. 36, no. S2, pp. 3873-3883, 2017.

[25] S. Shao, T. Hu, and P. Xu, "Discussion on research of mechanical characteristics of loess considering structural behavior and its application," Rock and Soil Mechanics, vol. 32, no. 2, pp. 42-50, 2011.

[26] L. Tang, "New suggestion on shear strength in unsaturated soil based on suction from grains," Chinese Journal of Geotechnical Engineering, vol. 4, pp. 412-417, 2001.

[27] Y. Zheng, H. Ye, and R. Huang, "Analysis and discussion on failure mechanism and fracture surface of slope under earthquake," Journal of Rock Mechanics and Engineering, vol. 28, no. 8, pp. 1714-1723, 2009.

[28] M. L. Lin and K. L. Wang, "Seismic slope behavior in a large scale shaking table model test," Engineering Geology, vol. 86, no. 2, pp. 118-133, 2006.

[29] L. M. Wang and Z. J. Wu, "Influence of site condition on seismic amplification effects during the Wenchuan earthquake," Journal Architecture Civil Engineering Environment, vol. 32, no. 2, pp. 175-8, 2010.

[30] A. Huo, J. Peng, Y. Cheng, X. Zheng, and Y. Wen, "Temporal characteristics of the rainfall induced landslides in the Chinese loess plateau (China)," in Recent Advances in Geo-Environmental Engineering, Geomechanics and Geotechnics, and Geohazards. CAJG 2018. Advances in Science, Technology \& Innovation (IEREK Interdisciplinary Series for Sustainable Development), A. Kallel, Ed., Springer, Cham, Switzerland, 2019.

[31] J. Qi, G. Zhao, Z. Zhang, and L. Wang, "Characteristics and mechanism analysis of loess earthquake damage in the Yongde Ms 5.8 earthquake in Gansu Province," Northwestern Seismological Journal, vol. 1, pp. 71-76, 1998.

[32] L. Gao, T. Zhu, and B. Lin, "Similar techniques for structural dynamic model test," Journal of Dalian University of Technology, vol. 1, pp. 1-8, 2000.

[33] J. Chen, L. Wang, X. Pu, F. Li, and T. Li, "Experimental study on the dynamic characteristics of low-angle loess slope under the influence of long- and short-term effects of rainfall before 
earthquake," Engineering Geology, vol. 273, Article ID 105684, 2020.

[34] L. Jiang, L. Yao, W. Wu, and G. Xu, "Discussion on application of transfer function analysis in shaking table model test of slope," Geotechnical Mechanics, vol. 31, no. 5, pp. 13681374, 2010.

[35] L. Jiang, L. Yao, and J. Wang, "Experimental similarity of slope shaking table model based on vibration behavior and damage similarity," Journal of Transportation Science and Engineering, vol. 2, pp. 1-7+18, 2009. 